\title{
Epidemiology of oral poisoning in paediatrics age group
}

\author{
Mangal Charan Murmu' ${ }^{1}$, Leena $\operatorname{Das}^{2}$ \\ ${ }^{1}$ Dr. Mangal Charan Murmu, Assistant Professor, ${ }^{2}$ Dr. Leena Das, Associate Professor, Department of \\ Paediatrics, S.C.B. Medical College, Cuttack, Odisha.
}

Address for Correspondence: Dr. Mangal Charan Murmu, E-Mail: mangal74murmu@yahoo.co.in

\begin{abstract}
Introduction: Poisoning in children is a common and preventable cause of morbidity and mortality. Our environment is still not child-safe and the medications are not dispensed in a child-safe manner. The incidence of childhood poisoning in India varies from 0.3 to 7.6 percent. Poisoning accounts for $0.03 \%$ of mortality in infants, $0.16 \%$ in preschool age group and $0.37 \%$ of in five to fourteen year's age group as per the statistics projected by Government of India. The poisoning in paediatric age group includes obsolescent traditional poisons, the in fashion intoxications with recreational drugs as well as chronic exposure to industrial chemicals. The peak incidence of accidental overdoses is in the second year of life and $85 \%$ of accidental poisoning affect children under five years of age. Methodology: This is a prospective case controlled study done over a period of two years. The study was conducted in S C B Medical College, Cuttack, Odisha. Results: The poisoning constitutes $1.15 \%$ of total paediatric admissions. The commonest type of poisoning was due to NonMedicaments (56 cases - 78.87\%), out of which the commonest poisoning was due to hydrocarbons. Conclusion: Non medicament ingestions particularly kerosene still one of the very common toxic ingestion in children used in accidental poisoning cases.
\end{abstract}

Keywords: Poisoning, Medicament, Non-medicaments, Pesticide, Hydrocarbon, Poisonous seed, Corrosive.

\section{Introduction}

Poisons are as old as mankind or perhaps even older. Their descriptions can be found in the ancient Egyptian, Babylonian, Hebrew and Greek literature. Poisons have been described in the Atharva Veda (1500BC), Kalpasthana, Chikitsasthana and Uttarasthana of the Shastras have described symptoms and antidotes of poisons in detail.

Sushruta (350BC) have described the procedures for incorporating poisons into foods, drinks, perfumes, medicine, bathing, water, snuff or sprinklers [1]. Poison is a substance that is capable of causing the illness or death of a living organism when introduced or absorbed. Toxicology is the branch of medical science which deals with the sources, pharmacokinetics and pharmacodynamics of poisons, the clinical manifestations produced by them, their lethal doses and the therapeutic

Manuscript received: $15^{\text {th }}$ April 2017

Reviewed: $25^{\text {th }}$ April 2017

Author Corrected: $4^{\text {th }}$ May 2017

Accepted for Publication: $10^{\text {th }}$ May 2017 measures to be employed to counter them [1]. Thus a variety of substances may act as poison including the medicines. The reported incidence of childhood poisoning in India varies from 0.3 to $7.6 \%$. Poisoning accounts for $0.03 \%$ of mortality in infants, $0.16 \%$ in the one to four years age group and $0.37 \%$ of mortality in five to fourteen year's age group as per the statistics projected by Government of India [2,3].

The peak incidence of accidental overdoses is in the second year of life and $85 \%$ of accidental poisoning affect children under five years of age [4]. High incidence of poisoning in preschool children is a direct consequence of the developmental stage of the child. As the infant begins to crawl, creep and then walk around one year of age, his human instincts lead him into exploring the environment, putting the objects into his mouth being a part of this exploration. By two and half to three years of age, child's motor development and ingenuity make accessible to him 
things potentially noxious. The fourth year of life heralds a decline in the incidence of accidental poisoning, not withstanding a further motor development and coordination as the child now tends to be selective in choosing things for purpose of ingestion, putting to good use his least experiences. Male children predominant the poisoning accidents accounted for by their greater degree of activity. The incidence tends to be higher among children from lower economic strata of society owing to poor storage facilities in such households and among children from larger families attributable to parental negligence. Under five children are considered especially vulnerable to poisoning for several reasons like mouthing activity continues to be prevalent after one year of age, exploring objects by tasting them is part of children's curious investigation, children's curiosity and ability to understand logical consequences and finally increased locomotion [5]. The present day households offer toxic substances at every corner including caustics, insecticides and medicines that provide an all too easy setting for childhood inquisitiveness to end in disaster. Most commonly the children ingest the agent which are easy assessable, colourful, attractive, good taste. The clinical symptoms may be the only clues to reach at diagnosis when we do not know the cause at the initial assessment and management.

Kerosene continues to be most commonly reported poison in the last four decades [6]. This study is undertaken to study to the pattern of oral poisoning in paediatric age group.

Objectives: Objective of our study is to study the epidemiological profile of oral poisoning in children and its outcome of those children admitted with various types of oral poisoning at paediatrics ward, S C B Medical College, Cuttack.

Period of Study: This study was done in the Department of paediatrics, S.C.B Medical College, Cuttack, a tertiary care referral hospital from January 2015 to December 2016.

Inclusion criteria: All the children from 1- 14 years of age of both sexes were admitted, with a history (established or suspected) of accidental, suicidal or homicidal ingestion of drugs or nondrugs (pesticides, hydrocarbons, Plant products, corrosives etc) were included in this study.

\section{Exclusion criteria}

a) Food poisoning cases were not included in this study because of difficulties in differentiation this disease entity from acute gastroenteritis.

b) Children having toxic or idiosyncratic reaction to the prescribed drugs and snake bite is excluded from study group.

c) Bee sting poisoning was not included.

The diagnosis of poisoning was based upon a detailed clinical history and a meticulous clinical examination followed by investigation.

Methods: This is a prospective case controlled study done over a period of two years from January 2013 to December 2015.

Sample size: Total 71 numbers of cases were included in our study. All the children fulfilling the inclusion criteria were taken into study in a prescribed format so that there will no bias. The observations obtained were interpreted in tables.

\section{Results}

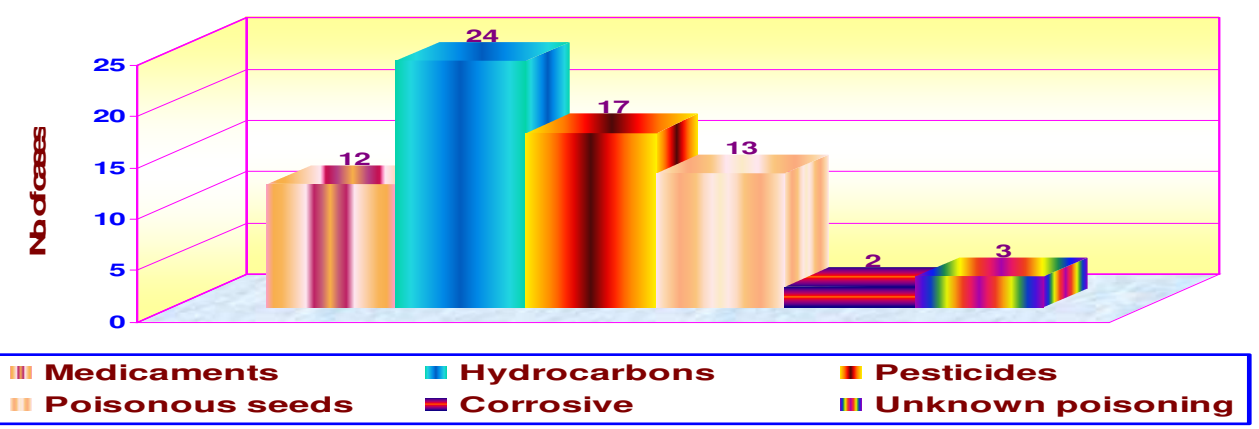

Figure-I: Incidence of various groups of poisons due to oral poisoning both established and suspected cases 
Out of the total oral poisoning the commonest type of poisoning was due to Non-Medicaments (56 cases $78.87 \%$ ), out of which the commonest poisoning was due to hydrocarbons. Unknown poisoning contributed only 3 cases $(4.22 \%)$.

Table-1: Age and sex distribution in the various types of poisoning.

\begin{tabular}{|c|c|c|c|c|c|c|c|c|c|c|}
\hline \multirow{2}{*}{ Poisons Group } & \multicolumn{2}{|c|}{$\mathbf{1 - 3}$ yrs } & \multicolumn{2}{c|}{ 4-5 yrs } & \multicolumn{2}{c|}{ 6-7 yrs } & \multicolumn{2}{c|}{ 8-14 yrs } & \multicolumn{2}{c|}{ Total } \\
\cline { 2 - 12 } & M & F & M & F & M & F & M & F & M & F \\
\hline Medicaments & 3 & 1 & 4 & 1 & 2 & 0 & 0 & 1 & 9 & 3 \\
\hline Non medicaments & & & & & & & & & & \\
\hline & 5 & 1 & 7 & 4 & 5 & 1 & 1 & 0 & 18 & 6 \\
Hydrocarbon* & & & & & & & & & & \\
\hline Pesticide** & 1 & 1 & 5 & 0 & 0 & 2 & 6 & 2 & 12 & 5 \\
\hline Poisonous seeds* & 2 & 1 & 0 & 0 & 0 & 0 & 4 & 6 & 6 & 7 \\
\hline Corrosive* & 0 & 0 & 0 & 0 & 2 & 0 & 0 & 0 & 2 & 0 \\
\hline Unknown poison & 1 & 0 & 0 & 1 & 1 & 0 & 0 & 0 & 2 & 1 \\
\hline Total 71 & 12 & 4 & 16 & 6 & 10 & 3 & 11 & 9 & 49 & 22 \\
\hline
\end{tabular}

*Non medicaments

Out of the total cases of poisoning due to all causes, 16 no of cases (22. 53\%) were 1-3 Yrs of age. 22 no of cases (30.98\%) were 3-5 Yrs of age. Out of the total 24 cases of hydrocarbon ingestion-17 cases $(70.83 \%)$ were below the age of 5 Years. Among poisoning seeds maximum no. of cases 10 (76.92\%) were age groups above 7 Years. Among the pesticides poisoning the maximum no. of cases $8(47.05 \%)$ was age group above 7 Yrs. There was no case below 1 year of age. The overall Male: Female ratio considering all the cases of poisoning is M: $\mathrm{F}=2.22: 1$.

Table-2: Mode of poisoning in the different age groups in oral poisoning.

\begin{tabular}{|c|c|c|c|c|c|c|c|}
\hline \multirow{2}{*}{$\begin{array}{l}\text { Mode of } \\
\text { poisoning }\end{array}$} & \multirow[t]{2}{*}{ Substance } & \multicolumn{4}{|c|}{ Age group in years } & \multirow[t]{2}{*}{ Total } & \multirow[t]{2}{*}{ Percentage } \\
\hline & & $1-3$ & $4-5$ & 6-7 & $8-14$ & & \\
\hline \multirow{6}{*}{$\begin{array}{l}\text { Accidental } \\
\text { ( Total 48) }\end{array}$} & Pesticidal poison & 2 & 4 & 0 & 0 & 6 & \multirow[t]{6}{*}{67.60} \\
\hline & Hydrocarbon ingestion & 6 & 12 & 5 & 0 & 23 & \\
\hline & Plant poison & 3 & 0 & 0 & 0 & 3 & \\
\hline & Medicament ingestion & 1 & 7 & 2 & 1 & 11 & \\
\hline & Corrosive & 0 & 0 & 2 & 0 & 2 & \\
\hline & Unknown & 1 & 1 & 1 & 0 & 3 & \\
\hline \multirow{6}{*}{$\begin{array}{c}\text { Suicidal } \\
\text { (Total 20) }\end{array}$} & Pesticidal poison & 0 & 0 & 0 & 8 & 8 & \multirow[t]{6}{*}{28.16} \\
\hline & Hydrocarbon ingestion & 0 & 0 & 0 & 1 & 1 & \\
\hline & Plant poison & 0 & 0 & 0 & 10 & 10 & \\
\hline & Medicament ingestion & 0 & 0 & 0 & 1 & 1 & \\
\hline & Corrosive & 0 & 0 & 0 & 0 & 0 & \\
\hline & Unknown & 0 & 0 & 0 & 0 & 0 & \\
\hline \multirow{6}{*}{$\begin{array}{c}\text { Homicidal } \\
\text { (Total 3) }\end{array}$} & Pesticidal poison & $\mathbf{1}$ & 1 & 1 & $\mathbf{0}$ & 3 & \multirow{6}{*}{4.22} \\
\hline & Hydrocarbon ingestion & $\mathbf{0}$ & $\mathbf{0}$ & $\mathbf{0}$ & $\mathbf{0}$ & $\mathbf{0}$ & \\
\hline & Plant poison & $\mathbf{0}$ & $\mathbf{0}$ & $\mathbf{0}$ & $\mathbf{0}$ & $\mathbf{0}$ & \\
\hline & Medicament ingestion & $\mathbf{0}$ & $\mathbf{0}$ & $\mathbf{0}$ & $\mathbf{0}$ & $\mathbf{0}$ & \\
\hline & Corrosive & $\mathbf{0}$ & $\mathbf{0}$ & $\mathbf{0}$ & $\mathbf{0}$ & $\mathbf{0}$ & \\
\hline & Unknown & $\mathbf{0}$ & $\mathbf{0}$ & $\mathbf{0}$ & $\mathbf{0}$ & $\mathbf{0}$ & \\
\hline Total & \multicolumn{2}{|l|}{14} & 25 & 11 & 21 & 71 & 100 \\
\hline
\end{tabular}


Out of the total 71 cases of oral poisoning 48 cases were Accidental (67.60\%), 20 cases (28.16\%) were Suicidal and only 3 cases $(4.22 \%)$ were Homicidal. All the 20 cases $(28.16 \%)$ of suicidal poisoning observed were under 7-14 years age group. The mode of poisoning in majority of the cases were suicidal 8 cases $(47.05 \%)$, Accidental cases were 6 (35.29\%), Homicidal cases were lowest i.e. 3 (17.64\%).Of the suicidal cases belong to age group 7-14 years 8 cases, (47.05\%). Out of total number of cases due to hydrocarbon poisoning, 23 cases i.e. $95.83 \%$ were Accidental and 1 case i.e. $4.17 \%$ was suicidal. Among 23 cases of Accidental, 12 cases were under $3-5$ yrs. of age group (50\%). Out of 23 cases of accidental, 18 cases $(75 \%)$ were below 5 years of age. Out of all the cases of plant poisons, 10 cases (76.92\%) were Suicidal and only 3 cases (23.07\%) were Accidental. All the Suicidal cases belong to the 7-14 years i.e. 10 cases (76.92\%).Out of the total cases of poisoning due to Medicaments 11 cases (91.66\%) were Accidental and only 1 case (8.33\%) was Suicidal. Among Accidental poisoning, 7 cases ( $>50 \%$ ) were under $3-5$ years age group.

Table-3: Time interval between ingestion and hospitalization of poisoning in cases from urban and rural settings.

\begin{tabular}{|c|c|c|}
\hline \multirow{2}{*}{ Urban /Rural } & \multicolumn{2}{|c|}{ Time interval between ingestion and hospitalisation } \\
\cline { 2 - 3 } & Range & Mean \\
\hline Urban & $0.5-4 \mathrm{hrs}$ & $1.76 \mathrm{hrs}$ \\
\hline Rural & $1-24 \mathrm{hrs}$ & $5.08 \mathrm{hrs}$ \\
\hline Overall mean time interval & & $4.01 \mathrm{hrs}$ \\
\hline
\end{tabular}

The mean time interval for cases from urban areas were $1.76 \mathrm{hrs}$. i.e. range $(0.5-4)$ hrs. and the mean time interval for cases from rural areas were $5.08 \mathrm{hrs}$. i.e. range $(1-24) \mathrm{hrs}$.

The overall mean time interval from ingestion to hospitalization was $4.01 \mathrm{hrs}$.

Table-4 : Time of onset of clinical features fallowing hydrocarbon poisoning

\begin{tabular}{|c|c|c|c|c|}
\hline \multirow{2}{*}{ Poisoning } & \multicolumn{2}{|c|}{ Time of onset of clinical features (post ingestion) } & \multirow{2}{*}{ Total } \\
\cline { 2 - 5 } & Lessthan $6 \mathrm{hrs}$ & $6-12 \mathrm{hrs}$ & Morethan $12 \mathrm{hrs}$ & \\
\hline Kerosene & 11 & 6 & 2 & 19 \\
\hline Turpentine & 1 & 0 & 0 & 1 \\
\hline Petrol & 1 & 0 & 0 & $\mathbf{2 1}(\mathbf{1 0 0} \%)$ \\
\hline Total & $\mathbf{1 3}(\mathbf{6 0 . 9} \%)$ & $\mathbf{6 ( 2 8 . 5 7 \% )}$ & $\mathbf{2}(\mathbf{9 . 5 2 \% )}$ & \\
\hline
\end{tabular}

Out of 24 cases of Hydrocarbon poisoning, 21 cases manifesting significant clinical features

Table-5: Different clinical manifestation with their percentage in cases with hydrocarbon poisoning.

\begin{tabular}{|c|c|c|}
\hline Clinical menifestation & No of cases & Percentage \\
\hline Vomiting & 15 & 61.18 \\
\hline Kerosene odour & 18 & 81.81 \\
\hline Fever & 11 & 50.00 \\
\hline Cough & 13 & 59.09 \\
\hline Drowsiness & 7 & 31.81 \\
\hline Breathlessness & 12 & 54.54 \\
\hline Abnormal lung finding & 13 & 59.09 \\
\hline Frothing at the mouth & 3 & 13.63 \\
\hline Pain abdomen & 5 & 22.72 \\
\hline Distension of abdomen & 3 & 13.63 \\
\hline Restlessness & 2 & 9.09 \\
\hline Cyanosis & 1 & 4.54 \\
\hline Asymptomatic & 3 & 13.63 \\
\hline
\end{tabular}


Among 21 cases, $13(61.90 \%)$ cases manifested clinical features before $6 \mathrm{hrs}$.

In kerosene poisoning, out of the 19 cases, 11 cases (57.89\%) manifested clinical features within $6 \mathrm{hrs}$.

Out of the total 24 cases due to hydrocarbon poisoning, 3 cases $(13.63 \%)$ were asymptomatic and of remaining 19 cases, the commonest manifestation was kerosene odour in the breath 18 cases, comprising $81.81 \%$ of the cases followed by vomiting 15 cases $(68.18 \%)$ and cough 13 cases $(59.09$

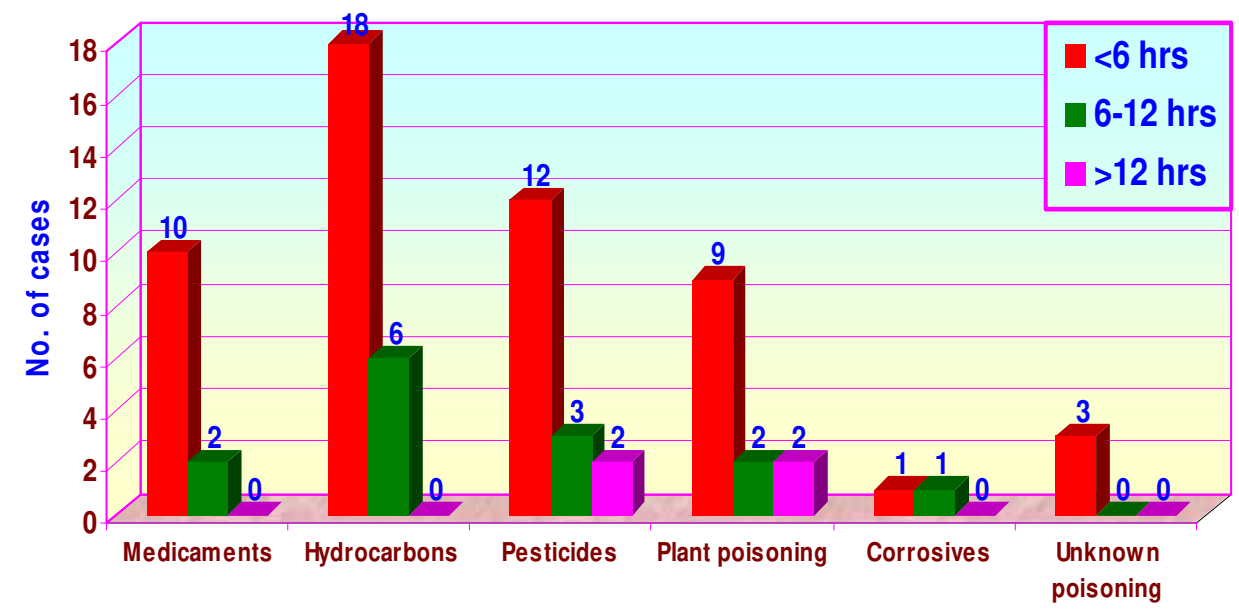

Figure-II: Relationship in time between ingestion and hospitalisation and outcome in cases of poisoning.

Out of 71 cases of poisoning $66(92.95 \%)$ cases were recovered and $5(7.04 \%)$ cases were death. Among the 5 cases of death 3 cases were under plant poisoning and 2 cases of pesticides.

Among 17 cases of pesticides, $2(11.76 \%)$ cases were dead. These two cases were hospitalized $>12$ hrs after ingestion.

Out of 13 cases of plant poisoning, 3 (23.07\%) cases were dead. Out of 3 cases of death 2 cases was hospitalized $>12$ hrs after ingestion.

Among 5 cases of death due to poisoning, 4 (80\%) cases were hospitalized more than 12 hours after ingestion of poisoning.

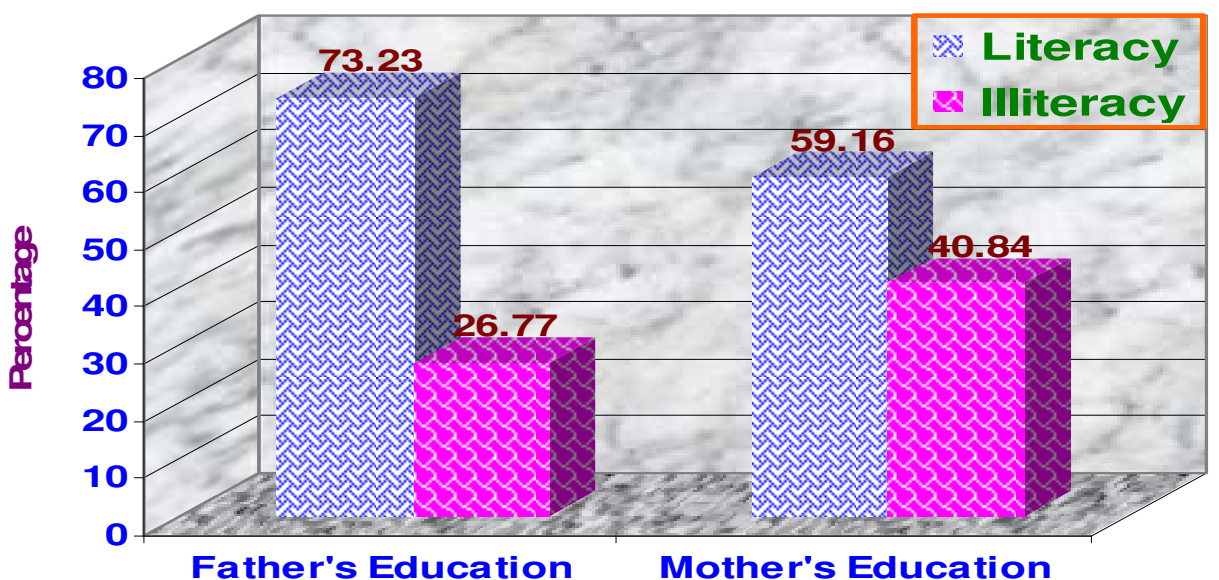

Figure-III: Showing distribution of cases as per group poisoning and parentral literacy

Out of 71 cases of poisoning, $52(73.23 \%)$ cases fathers are literate and $19(26.77 \%)$ cases fathers are illiterate, $42(59.16 \%)$ cases mothers are literate and $29(40.84 \%)$ cases mothers are illiterate. 


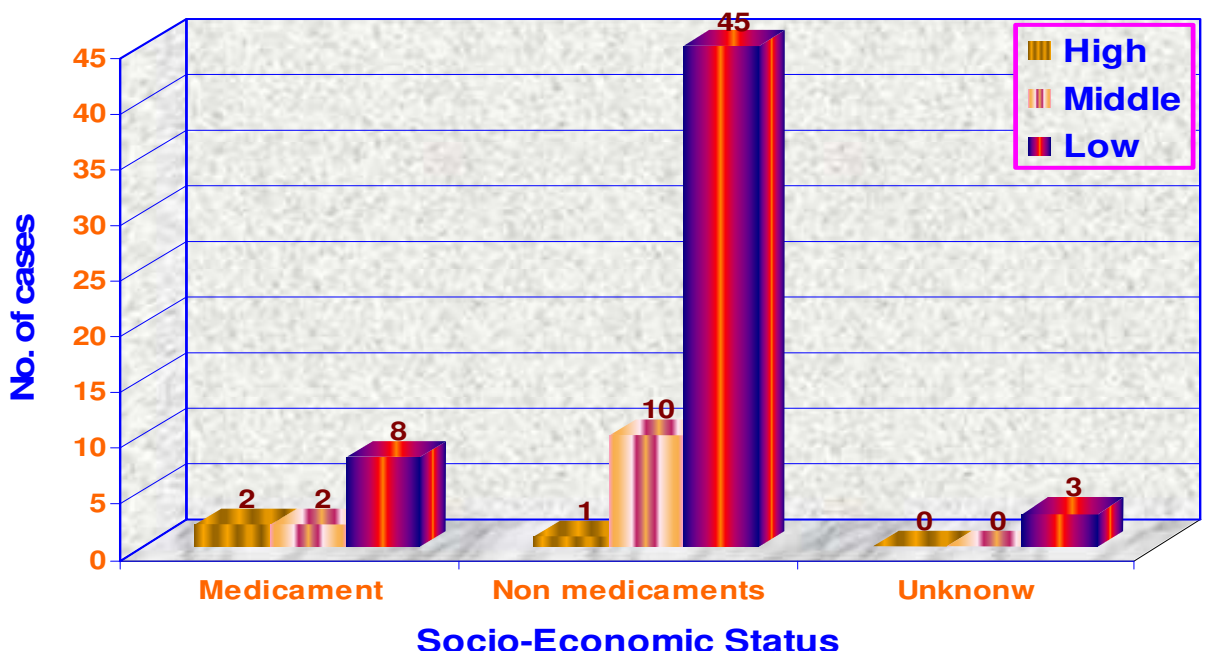

Figure-IV: Distribution of cases as per group of poisoning and socio-economic status.

Out of 71 cases of poisoning, 56 (78.87\%) cases were recorded among families having low socio-economic status ( $<$ Rs. $2000 /$ - per month), Only 3 cases $(4.22 \%)$ were recorded among families having high socio economic status (> Rs.3000/- per month).

Table-6 : Showing relation of number of sibling present, birth order of child, type of family, associated risk factor, school performance in poisoning.

\begin{tabular}{|c|c|c|c|c|c|c|c|c|c|c|c|c|}
\hline \multirow{2}{*}{$\begin{array}{c}\text { Type of } \\
\text { poisoning }\end{array}$} & \multicolumn{3}{|c|}{$\begin{array}{c}\text { Number of } \\
\text { sibling } \\
\text { present }\end{array}$} & \multicolumn{2}{|c|}{$\begin{array}{c}\text { Birth } \\
\text { order of } \\
\text { child }\end{array}$} & \multicolumn{2}{|c|}{$\begin{array}{l}\text { Type of } \\
\text { family }\end{array}$} & \multicolumn{2}{|c|}{$\begin{array}{l}\text { Associated risk } \\
\text { factor }\end{array}$} & \multicolumn{3}{|c|}{$\begin{array}{c}\text { School } \\
\text { performance }\end{array}$} \\
\hline & $\mathbf{0}$ & $\begin{array}{l}\leq \\
2\end{array}$ & $\begin{array}{l}\geq \\
\mathbf{3}\end{array}$ & $\leq 2$ & $\geq$ & Nuclear & Joint & \begin{tabular}{|r|}
$\begin{array}{r}\text { Parent's } \\
\text { Reprimand }\end{array}$ \\
\end{tabular} & $\begin{array}{l}\text { Failure } \\
\text { in love }\end{array}$ & $\begin{array}{c}\leq \\
49 \%\end{array}$ & $\begin{array}{c}50-59 \\
\%\end{array}$ & $\begin{array}{r}\geq 60 \\
\%\end{array}$ \\
\hline Medicaments & 1 & 5 & 6 & 10 & 2 & 8 & 4 & 0 & 1 & 1 & 0 & 0 \\
\hline \multirow{3}{*}{$\begin{array}{c}\text { Non } \\
\text { medicaments } \\
\text { hydrocarbon } \\
\text { plant poisoning }\end{array}$} & & & & & & & & & & & & \\
\hline & 0 & 9 & 15 & 16 & 8 & 14 & 10 & 1 & 0 & 0 & 1 & 0 \\
\hline & 1 & 7 & 9 & 16 & 1 & 0 & 2 & 6 & 4 & 8 & 1 & 1 \\
\hline Pesticide & 0 & 3 & 10 & 12 & 1 & 8 & 9 & 5 & 3 & 8 & 0 & 0 \\
\hline Corrosive & 0 & 0 & 2 & 1 & 1 & 3 & 0 & 0 & 0 & 0 & 0 & 0 \\
\hline Unknown & 1 & 2 & 0 & 3 & 0 & 3 & 0 & 0 & 0 & 0 & 0 & 0 \\
\hline 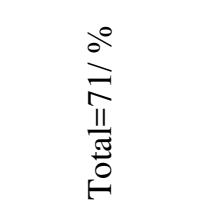 & 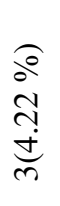 & 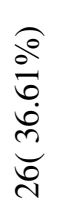 & 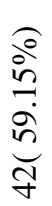 & 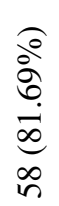 & 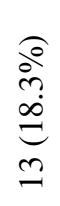 & 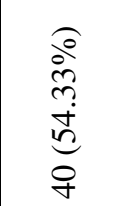 & 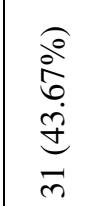 & 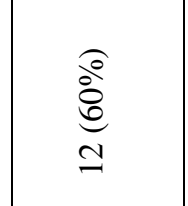 & 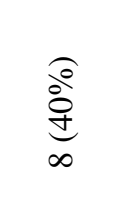 & 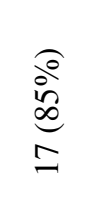 & 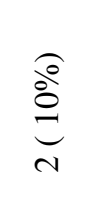 & $\stackrel{0}{i}$ \\
\hline
\end{tabular}

Out of 71 cases, poisoning were found in $42(59.15 \%)$ cases having 3 or more numbers of siblings, $58(81.69 \%)$ cases were observed associated with birth order of $1^{\text {st }}$ or $2^{\text {nd }}, 40(56.33 \%)$ cases were observed in nuclear families and $31(43.67 \%)$ cases were observed in joint families.

Among 20 cases of suicidal poisoning $12(60 \%)$ cases associated with parent's reprimand and $8(40 \%)$ cases associated with failure in love, $17(85 \%)$ cases associated with poor school performances $(<50 \%$ marks in Exam.), 1 (5\%) cases having good school performance ( $>60 \%$ marks in Exam). 


\section{Discussion}

In this study, the overall incidence of oral poisoning was $1.15 \%$ out of the total 6129 admissions to the paediatric ward of S C B Medical College, Cuttack.It was observed that the incidence of oral poisoning in the present series was more or less in conformity to the previous studies by Sharma et al (1.28\%) [7]. Jadhav S et al(1.3\%) [8], Ghosh V B et al (1.05\%) [9]. Tarvadi VK et al [10] however noted higher $4.7 \%$ incidence of poisoning.

Out of the total 71 cases of oral poisoning more than $50 \%$ were below 5 years and a substantial proportion occurred above 7 years as shown by Table-I. The finding in the present series are in conformity to that Jadhav S et al 85\%[8], Ghosh et al $80.7 \%$ [9], Roy MP et al 75\%[11], Bhat NK et al $69 \%$ [12], however Kohli U et al [13] studies earlier age of presentation of 1-3 years presentation $(63.9 \%)$.

In the present series, the overall sex ratio (M:F) was a 2.22:1 with the male out numbering the females in most of the age groups. Similar to the observation by Kohli U et al[13]. Sharma et al have studied a ratio of 1.17:1, Bhat NK et al [12] and Budhathoki S et al [14] have found a ratio of 1.4:1. However study done by Devaranavadagi RA et al [15] showed a reverse ratio.

In the present series $32.39 \%$ were from the urban area, whereas $67.60 \%$ were from the rural areas with a urban: rural ratio of 1:2 (Table -II). This was in conformity to the study by Sharma et al [7], Bhat NK et al [12] and Rajendra Singh et al [16].

In the present series, among all the cases of poisoning, the commonest poisoning was due to non medicaments (78.87\%), followed by medicaments $(16.90 \%)$ and unknown poisoning $(4.22 \%)$, as shown in the picture- I. This could be due to common knowledge about non medicament toxic agents as suicidal agent as well as easily available at home which is responsible for accidental ingestion by small children. On further analysis of non medicaments, Hydrocarbon (33.80\%), Pesticides (23.94\%), Poisonous Seeds (18.30\%) and Corrosive (2.81\%) were the common poisons $[13,14]$. In the present series among all oral poisons Hydrocarbon topped the list, similar to the observation b Jadhav S et al [8], Ghosh et al
[9], kohli U et al [13], Rajendra Singh et al [16 ]. This could be because of its common use as domestic fuel in low socio-economic classes where most of the cases were seen.

But Devaranavadagi RA et al [15] in their study observed the highest incidence $34 \%$ due to medicine and chemicals. Roy MP et al [11] and Jayashree $M$ et al [17] have found that drugs causing poison in $26.7 \%$ and $17 \%$ of cases.

In the present series of the total cases $67.60 \%$ was accidental and $28.16 \%$ was suicidal and only $(4.22 \%)$ was Homicidal. The figure obtained in the present series was in conformity to the study Devaranavadagi RA et al [15], Jayashree $M$ et al [17].

\section{Non Medicaments}

Hydrocarbons- There were 24 cases of hydrocarbon ingestions, 22 cases due to kerosene, 1 case due to Turpine oil and 1 case due to petrol. The hydrocarbon poisoning comprised $33.80 \%$ of total poisoning.

The incidence of kerosene in the present series, $33.80 \%$ was in agreement with studies by Jadhav $\mathrm{S}$ et al [8], Rajendra Singh et al [16] Kohli U[13], N $\mathrm{P}$ Modi et al[18 ]. But slightly lower incidences as compared to Sharma $\mathbf{J}$ et al [7], as in the present situation peoples are used cooking gases as compared to kerosene.

Out of the total 24 cases of hydrocarbon ingestion, 21 cases became symptomatic including 1 case of petrol and 1 case of tarpine and 3 remained asymptomatic. Out of 19 patients with kerosene poisoning who became symptomatic, 11 developed signs and symptoms within 6 hrs. (57.89\%).

Other hydrocarbon cases like 1 case of tarpine oil and 1 case of petrol developed sign and symptom within 6 hours.

Among the various clinical features of kerosene poisoning, the commonest was kerosene odour $(81.81 \%)$ followed by vomiting $(68.18 \%)$, cough $(59.09 \%)$ and fever $50 \%$. This was in conformity with the study by Rathore $S$ et al [19], but at variance with that of Ganga N et al [20]. 
The quantity of kerosene ingested could not be assessed probably, but it seemed that it was not more than $10-15 \mathrm{ml}$ in the majority of cases, similar to the observation by Rathore $S$ et al [19] and Ganga $N$ et al [20].

Among hydrocarbon poisoning, 95.83\% were accidental and $4.17 \%$ were suicidal. This can be explained, because since most of the cases occurred below 5 years, the nature of the liquid could not be differentiated by these little children.

There was no fatality due to this category of poison in the present series, which was in conformity with earlier studies by Rathore $S$ et al [19]. , but differed from the studies by Ganga $\mathrm{N}$ et al [20]. This content was due to the amount ingested which was probably small in this series.

The incidence of insecticidal poisoning was $23.94 \%$ out of all poisoning. Out of the $23.94 \%$ due to insecticidal poisons, organophosphorus poisoning was the commonest $(52.94 \%)$ followed by Rhodenticides (23.52\%) and Organochlorine $(11.76 \%)$ and the least common varieties was due to Naphthalene 5.8\% and Louse killer 5.88\%.

The incidence of pesticidal poisoning in the present series was more compared to the studied by Sharma $\mathrm{J}$ et al [7], Kohli U[13], Jayashree $\mathrm{M}$ et al [17], and Ganga $N$ et al[20]. The higher incidence of pesticidal poisoning in the present series was probably due to the increased domestic and particularly agricultural use of pesticides in the rural areas, from which most of the cases came.

Among pesticidal poisoning the vast majority were from rural areas $(52.94 \%)$ and the remaining from the urban. The high reporting from rural areas is due to their increased agricultural use in the rural areas. About $64.70 \%$ cases in poisoning due to pesticides manifested within 30-60 mins. of ingestion. Out of the total cases $88.23 \%$ were brought within $12 \mathrm{hrs}$ of ingestion.

Out of the total cases $(11.76 \%)$ were death, and these cases were hospitalized after $12 \mathrm{hrs}$ of ingestion. In the present series mortality due to pesticide poisoning was reported $(11.76 \%)$, which was in conformity to studies by Ahmed et al [21] and Gupta et al [22]. Poisoning due to poisonous seeds and other plant poisons constituted $18.30 \%$.
Sharma et al [7] reported $21.8 \%$ of cases due plant poisoning, similar figure compared to the present series was done by Ganga $\mathrm{N}$ et al [20]. The plant poisoning, comprised mainly of oleander $(76.92 \%)$ and Dhatura (23.08\%). Most of the cases occurred above 7 years of age $(76.92 \%)$ with an overall male female ratio of $0.9: 1$ and $61.53 \%$ belonged to the rural areas. It is natural that a major proportion of cases $(61.53 \%)$ reported from the rural areas, where there was easy availability of various poisonous plants.

Dhatura was the commonest type of plant poison in the studies by Ganga N et al [20] which was not consistent with the present study. Poisoning due to oleander was reported by Gupta et al [22] which was in conformity with the present series.

This variation of the distribution in plant poisoning was due to the fact that, regional differences exist with respect to the availability of the various plant poisons, with easy availability of some plant poisons in some parts of the country. In view of their easy availability in rural Orissa, it is natural that poisoning with these was observed in the present study. Out of the total cases of plant poison $(23.07 \%)$ were death, most of the cases are hospitalized more than $12 \mathrm{hrs}$ after ingestion.

Medicaments: Poisoning due to medicaments constituted $16.90 \%$ (Figure-I) of the total poisoning. This figures obtained in the present series considerably low compared to the previous studies of, Sharma et al[7] and Ganga N et al [20]

The low incidence of medicaments poisoning in the present series is probably due to the fact that a sizable proportion of the cases belonged to the rural areas, where poisoning due to medicaments was naturally low.

In the present series among medicaments, Dapsone was the commonest $25 \%$ followed by Carbamzepine and Phenytoin each (6.66\%). The other substances were DEC, Olanzepine, Amlodepine, Alprazolam and Gama-benzenehexachloride. Various authors like Gupta et al[22], Ganga N et al [20] and Satpathy et al reported varying incidences due to phenothiazine poisoning which was not seen in the present series.Opium poisoning was reported by Ganga $\mathrm{N}$ et al[20] unlike in the present series. 
Ganga $\mathrm{N}$ et al[20], Satpathy et al reported varying incidence of salicyclate poisoning unlike in the present series.

Only 2 cases of corrosive poisoning were documented due to Nitric acid constituting 2.81\% of all poisoning. Poisoning due to corrosives was least common. The incidence of corrosive poisoning in the present series was much low compared to the study of Roy MP et al[11] and Jayashree $\mathrm{M}$ et al [17] among others.

The time interval between ingestion and hospitalization varies in urban and rural settings. In cases from urban areas the mean time interval was 1.76 hours and in cases from rural areas the mean time interval was $5.08 \mathrm{hrs}$. The overall mean time interval was 4.01 hours. From the above figures it can be interfered that time taken for hospitalization following ingestion was considerably shorter in urban cases. The shorter time interval for urban cases was probably because of the proximity to the hospital and better facilities for transportation. The observations in the present study were consistent with that of sharma et al [7].

In this study those child was taking poisons their parents education, socio-economic status, nature of family, siblings history, birth order history, school performance and risk factors were recorded.

Literacy Rate 2011 census of female is $65.46 \%$, where the male literacy rate is over $80 \%$. But in this study $73.23 \%$ males are literal and $40.84 \%$ female are literate. No significant correlation in observed with incidence of poisoning and parents literacy.

$78.87 \%$ cases earned a per capita income of less than Rs.2,000/-, 16.90\% of between Rs.2000-3000 and $4.22 \%$ cases were of more than Rs.3,000/- per capita income. Sharma et al [7] had similar study like us.

A significantly higher incidence $(59.15 \%)$ cases of poisoning has been observed in children having 3 or more siblings. This high incidence is probably due to lack of parentral supervision in families having large number of children. In present study $81.69 \%$ of cases of poison has been observed in children having birth order less than on equal to two. This high incidence is probably due to lack of parentral supervision on elder children. In the present study significantly $56.33 \%$ cases due to poisoning occurred in nuclear families. If appears that in joint families number of inmates are more compared to nuclear families and they are able to devote more time to the care of their children.

Significantly $(60 \%)$ cases of suicidal poisoning associated with parent's reprimand and $40 \%$ cases associated with failure in love. As most of the cases are in teenage groups, the age at which the adolescent are vulnerable for emotional disturbance because of increasing demands by parents for academic performance and improper handling of adolescent behaviour attitude towards opposite sex.

In the present study $85 \%$ cases of suicidal poisoning associated with poor school performance.

The over all burden of mortality in our study was $7.04 \%$. The study done by NP Modi et al [18] had mortality of $7 \%$, Sharma et al [7]6.18\%, Mandal A et al [22]6.67\% , and as low as $1.87 \%$ by Rajendra Singh et al [16]

\section{Conclusion}

Non medicament ingestions particularly kerosene still one of the very common toxic ingestion in children used in accidental poisoning cases. Pesticides are also an equally common toxic ingestion used mostly by elderly children and adolescents. For suicidal attempt organophosphorus and Rhodenticide are the common agents used. Poisoning is a common low socio-economic groups, children of nuclear families.

There was higher incidence of poisoning in males compared to females in present series cause which is not well explained. Accidental ingestion of toxic agents is still the common reason for admission of all poisoning cases. Hydrocarbon ingestion carries had better outcomes compared to ingestion of other common agents like pesticides, poisonous seeds. Literacy of parents had direct bearing for seeking medical help in cases of toxic ingestion.

Families having larger number of children are more vulnerable for toxic ingestion. Parent's reprimand and failed love and poor academic performance are common reasons responsible for suicidal attempts by children. 


\section{Suggestions}

*IEC activities should be made in term of awareness about need for proper storage of Kerosene, Pesticides, Rhodenticides and Medicaments beyond reach of children.

*Adolescent guidance programme should be started in school along with involvement of parents.

*Emergency medication and common antidotes should be made available at primary health care facilities.

*Prescribers should properly advice for the safe handling of medicaments and keep beyond of reach of children.

\section{Funding: Nil, Conflict of interest: None Permission of IRB: Yes}

\section{References}

1. Utpal Kant Singh, FC Layland, Rajniti Prasad, Shivani Singh (eds), Poisoning in Children Indian J Pediatr (2013) 80: 798.

2. Singh S, Singhi S, Sood NK, Kumar L, Walia BNS. Changing pattern of childhood poisoning (1970-1989): experience of a large, north Indian hospital. Indian Pediatr 1995; 32: 331-6.

3. Khadgawat R, Garg P, Bansal P, Arya A, Choudhary B. Accidental poisoning. Indian pediatrics. Volume-31 December 1999:1555-1557.

4. Basu M, Kundu T K, Dasgupta M K, Das D K, Saha I, Poisoning, Sting and Bites in children-what is new ? An experience from a tertiary care hospital in Kolkata Indian Journal of Public Health Vol. 53 No4 October-December.2009.

5.Petridou E, Kouri N, Polychronopoulou A, Siafas K, Stoikidou M, Trichopoulos D. Risk factors for childhood poisoning: a case-control study in Greece. Inj Prev. 1996 Sep;2(3):208-11.

6. Gupta P, Singh RP, Murali MV, Bhargava SK, Sharma P. Kerosene oil poisoning--a childhood menace. Indian Pediatr. 1992 Aug; 29 (8): 979-84.

7. Sharma J, Kaushal RK. Profile of Poisoning in Children. Pediatric Oncall 2014;11(2): DOI : 10. 7199 /ped.oncall.2014.28.
8. Jadhav S, Rathi S, Biakthansangi B, Kondekar S. Clinical profile of poisoning in children: A hospital based study. Int J Contemp Pediatr 2016;3:709-1

9. Brata Ghosh V, Jhamb U, Singhal R, Krishnan R. Common childhood poisonings and their outcome in a tertiary care center in Delhi. Indian J Pediatr. 2013 Jun; 80 (6): 516-8. doi: 10.1007/s 12098 -012-0879-5. Epub 2012 Sep 2.

10. Tarvadi VK, Bakkannabar SM, Manjunath M, Palimar V, Kumar GP, Shetty M. Trend of poisoning among children at Kasturba Hospital, Manipal. NUJHS Vol-3, no 2, June 2013, ISSN 2249-7110.

11. Roy MP, Gupta R, Bhatt M, Aggarwal KC. Profile of Children Hospitalized with Acute Poisoning in New Delhi. Indian Pediatr. 2017 Mar 15; 54(3):246-247. Epub 2017 Feb 2.

12. Bhat NK, Dhar M, Ahmed S, Chandar V. Profile of poisoning in children and adolescent at North Indian territory care center. J Indian Acad Clin Med 2011;13:37-42.

13. Kohli U, Kuttiat VS, Lodha R, Kabra SK. Profile of childhood poisoning at a tertiary care centre in North India. Indian J Pediatr. 2008 Aug;75(8):791-4. doi: 10.1007/s12098-008-0105-7. Epub 2008 Jun 25.

14. Budhathoki S, Poudel P, Bhatta NK, Dutta AK, Shah GS, Bhurtyel KK, Agrawal B, Sribastava MK and Singh MK. Clinical profile and outcome of poisoning and intoxication in children: A hospital based study. Nepal Med Coll J 2009;11(3):170-175

15. Devaranavadagi RA, Patel S, Shankar P. A study on profile of poisoning in pediatric population. Int J Contemp Pediatr 2017;4:1-6.

16. Rajendra Singh, Shalender Kumar. Study of Current Trends of Poisoning in Children in Bikaner Region. Int J Med Res Prof. 2017; 3(1):153-55

17. Jayashree M, Singhi S. Changing trends and predictors of outcome in patients with acute poisoning admitted to the intensive care. J Trop Pediatr. 2011 Oct;57(5):340-6. doi: 10.1093/tropej /fmq099. Epub 2010 Oct 26. 
18. Narayan Prasad Modi, Braja Kishore Dash, Smita Satapathy, Anil Kumar Mohanty Trends of Acute poisoning cases in a tertiary care hospital in Odisha, India: a prospective study, IOSR-JDMS, 2014,13:11; 12-17

19. Rathore S, Verma AK, Pandey A, Kumar S. Pediatric poisoning trend in Lucknow District, India. J Forensic Res 2013;4: 179.

20. Ganga N, Rajarajeswari G. Poisoning in children. Indian Pediatr. 2001 Feb;38(2):208.
21. Ahmad SH, Fakhir S, Gupta S, Singh RK. Celphos poisoning. Indian Pediatr. 1991 Mar; 28 (3):300-1.

22. Gupta P, Singh RP, Murali MV, Bhargava SK, Sharma P. Kerosene oil poisoning--a childhood menace. Indian Pediatr. 1992 Aug;29(8):979-84.

23. Mandal A, Pal AC, Das PK, Dutta AK. Clinicoepidemiological profile of poisoning in children in a rural based medical college and hospital. IOSR J Dent Med Sci 2016;15:50-5.

\section{How to cite this article?}

Mangal Charan Murmu, Leena Das. Epidemiology of oral poisoning in paediatrics age group. Int J Med Res Rev 2017;5(07):769-779.doi:10.17511/ijmrr. 2017.i07.17. 